\title{
Wakening the serpent: reflections on the possible modification of the Euratom Treaty
}

\author{
Nuria Prieto Serrano \\ Legal Advisor, \\ Corporate Management Division, \\ Enresa, c/Emilio Vargas, 7, Madrid 28043, Spain \\ E-mail: nprs@enresa.es
}

\begin{abstract}
Directives acquired in the framework of the Kyoto Protocol and the fact that the nuclear energy production does not generate carbon dioxide, might point to a recovery by the nuclear energy industry, which would be possible only within a more or less lengthy process of social confrontation in the Member States. While new scenarios for the European energy supply are being configured, the nuclear energy option remains open in many countries. Meanwhile, the Treaty establishing the European Atomic Energy Community (Euratom) remains in force without having undergone any substantial change, as it was drawn up, many of its provisions being in a sense latent or awaiting an eventual decision regarding the use. This paper describes certain attempts made to reform the Euratom Treaty and the reasons for which they failed.
\end{abstract}

Keywords: EU Primary Law; European Convention and Constitutional Treaty; Euratom reform.

Reference to this paper should be made as follows: Proeto Serrano, N. (2006) 'Wakening the serpent: reflections on the possible modification of the Euratom Treaty', Int. J. Nuclear Law, Vol. 1, No. 1, pp.11-18.

Biographical notes: Nuria Prieto Serrano graduated in Law at Madrid in 1999. She is a specialist in European Community Law (Diploma in European Studies, University of Saarland, Saarbrücken, 2001). From 2002 to 2003, she was a stagiaire in the European Commission, specialising in Nuclear Law. She received a diploma with honours at the International School of Nuclear Law (OECD-NEA/University of Montpellier) and is currently doing her $\mathrm{PhD}$ on the Euratom Treaty (DEA defended in June 2005). She has been a Legal Adviser in Enresa since 2003 and a collaborator with the Ministry of Industry, Tourism and Trade in common areas of interest.

\section{Introduction: a discrete treaty}

A treaty that is not undergoing reform cannot be regarded as newsworthy, so for that reason this paper is of little interest for those looking for some breaking news. In the case in hand, the lack of news is the best possible news; it is what guarantees the continued existence of the Euratom Treaty.

What might be considered noteworthy is the fact that, within the dynamic process of European integration, a foundational treaty should not be varied significantly, as it was drawn up, even though directives for the simplification of Primary Law have been 
proposed within the framework of the European Council and unprecedented efforts have been made in this aspect through the announcement of a Convention. ${ }^{1}$ Having passed the examination of the European Convention without alterations is something that confirms the peculiar nature of the Euratom Treaty. To date, no other Community text has achieved such longevity.

With a view to putting things into context, we briefly refer the reader to the constitution in 1951 of the European Coal and Steel Community (ECSC), through the Treaty of Paris, which would be later followed by the European Economic Community and the European Atomic Energy Community or Euratom, in the Treaties of Rome (1957). At this time, the civil nuclear development generated great expectations regarding the achievement of energy supply in a secure and an inexpensive way. The Euratom Treaty reflected that hope and unequivocally endorsed the nuclear energy option. Nowadays, especially after the Chernobyl accident (1986), the predominant attitude towards nuclear energy is quite different; however, the provisions of the Euratom Treaty have not been modified in this period.

Repeatedly, the sketch of a new constitutional text for Europe has brought up a question that has been repeatedly posed in the last few decades: the eventual updating, or even the repeal, of the Euratom Treaty. Although its reform was once again proposed within the framework of the European Convention, the issue was settled with a brief announcement:

Given the Convention's terms of reference and its timetable, the Praesidium believes that there is no basis for the Convention to become involved in an operation to amend the Euratom Treaty substantially, nor would it be appropriate for it to do so. ${ }^{2}$

Indeed, the mandate of the Convention had been defined as being much more a task of simplifying texts than of substantially modifying Community policies, and reforming the contents of Euratom would have involved substantial changes. In short, the old Treaty was adapted to the new constitutional text through a protocol, with minimal interference in its contents - the proposed reform covers only the institutional and financial provisions of the Treaty (parts III and IV). However, this transformation of the text into a protocol will not influence the status of Euratom as an instrument of Primary Law. ${ }^{3}$

\section{Reasons for and against the change}

Recently, the reform of the Euratom Treaty has been taken into the arena of public debate, with the following arguments:

1 The social perception of nuclear energy, and consequently its political acceptance and economic weight, is not the same as it was in 1957, as a result of which a Treaty promoting nuclear energy should not remain in force.

2 The need to maintain certain parts of the text that have either fallen into disuse or have never been used is not understood. This statement is particularly applicable to the provisions on security of supply and ownership (Chapters 6 and 8 of the first part). 
3 Unlike the ECT, the Euratom Treaty has not evolved with regard to the procedure foreseen for decision-making. Since 1957 decisions have been taken within the framework of Euratom by qualified members in the Council. On the other hand, the ECT has extended to numerous Union policies the more democratic procedure of co-decision, with active participation of the European Parliament. The Parliament for years has been attempting to extend its sphere of intervention in Euratom, with a little result to date. ${ }^{4}$

4 An internal market regime based on the ECT is being implemented in the electricity sector, and the issue as to whether the nuclear energy market should be regulated by a different special regime is a much-debated aspect. Special emphasis is laid here on the system of State aids. The question of State intervention in the nuclear energy sector is subject to opposing approaches in the ECT and in Euratom and in principle both the Treaties enjoy the same position and binding force in the Community legal system of sources. ${ }^{5}$

It is a fact that the nuclear energy industry needs heavy injections of capital in the initial phase, until such time as it becomes economically profitable: the construction of nuclear power plants, research centres and other facilities in every phase of the fuel cycle are expenses that cannot be met by private initiative without the backing of the State. This backing was promoted in the 1950s by all the international authorities, among them Euratom, which establishes a framework for all those States wishing to do so to develop and strengthen their nuclear resources and participate in common investment projects. It is obvious that this philosophy in favour of public investment necessarily runs contrary to the control to which State aids are subjected in the general Community regime. With this approach, the Euratom Treaty does not establish any specific system controlling State aids similar to that imposed by the ECT.

Given the absence of the Euratom Treaty provisions comparable to Articles 87 to 89 of the ECT, there are a wide variety of opinions regarding the application of these articles of the ECT to the nuclear sector. The issue, discussed by the doctrine, has important practical consequences. ${ }^{6}$

5 The ECSC Treaty fulfilled its legal lifetime and the coal and steel market has become integrated in the general energy regime. Although it is true that it does not have a foreseen term of expiration, as was the case for the ECSCT, a similar evolution for the Euratom Treaty might be possible.

It is even surprising that the Euratom Treaty would not have undergone any significant alteration to-date. Compared with the continuous process of evolution experienced by the (E)ECT, the Euratom Treaty has remained unchanged over the years, becoming embedded in a manner that is inconvenient for those who have unsuccessfully postulated its reform. This might be explained mainly for the following reasons:

1 The Member States address with an extreme political precaution any decisions relating to nuclear issues. In this area that is so sensitive to public opinion, the status quo is often more beneficial for a Government than any type of reform.

2 An unarguable merit of the text is its great adaptability. It is designed on the basis of two goals: promotion, on the one hand, and protection, on the other hand. This circumstance has allowed it to serve over the years to defend widely differing interests, and this has contributed for practical reasons to its reform being avoided. 
3 The Treaty confers on the Member States a large degree of autonomy with regard to action. It establishes common frameworks in areas such as the security of supply or the protection of health, but does not impose any specific nuclear policy. Adherence to the chapters dealing with investments or research is voluntary. This has meant that to-date the States have felt little or no need to reform it.

This is an extremely delicate and difficult task. Changing a part of the text necessarily means altering the structure of a Treaty that to-date has been maintained in a difficult state of equilibrium. The military implications of certain provisions of the Treaty and the sensitivity of the issue of energy supply increase the difficulty of any debate on change.

\section{The Euratom Treaty and its 'ability to learn': a process designed for specific reforms}

In the Euratom Treaty, we find some articles that allow certain modifications to its text. These are provisions in the end of three chapters of the first part:

- In Chapter 6, on supply: Art. 76.

- In Chapter 7, on safeguards: Art. 85.

- In Chapter 8, on the system of ownership: Art. 90.

These articles are written in parallel: whenever new circumstances so require, the Council may unanimously, in response to proposals by the Commission and following consultation with Parliament, reform certain provisions of the corresponding chapter. Articles 85 and 90 also allow a Member State to undertake the initiative of a reform, as long as this is reviewed by the Commission. Furthermore, Article 76 foresees a process of reform of its corresponding chapter, a process that should have been carried out seven years after the Treaty was drawn up, but was not. ${ }^{8}$

The indeterminate condition of these articles (whenever new/unforeseen circumstances so require...) makes them a clause for flexibility in the Treaty - as in Art. 203, similar to 308 ECT, from a different perspective. Both allow the Community to take actions in areas not contemplated in the Treaties, with the requirement that there be unanimity in the Council and as long as such actions reasonably serve the objectives of the Union.

The doctrine has referred to these articles as the 'ability to learn of the Treaty', inasmuch as they allow for specific improvements to the text without leading to debate regarding the text overall; thus, avoiding the procedure of Art. 48 EUT, ${ }^{9}$ which calls for the holding of an Inter-Governmental Conference, etc. These provisions demonstrate the caution with which the Treaty was written in 1957 or, what amounts to the same, the extent to which its authors were aware of the delicacy of addressing reforms in any areas relating to nuclear policy.

The reason underlying these atypical provisions is precisely that of these chapters $-6,7$ and 8 of the first part - and most especially the sixth were written provisionally. It should be remembered that the nuclear energy industry began its development in Europe during the 1960s and that in 1957, the year in which the Treaty 
was drawn up, it was not possible to foresee how aspects such as trade in nuclear material or weapons development might evolve. This uncertainty is reflected particularly in the three aforementioned chapters of the Treaty, and not in others with respect to which there was greater certainty regarding their durability.

The fact is that to date articles 76-85-90 have not been used to fulfil their objectives. ${ }^{10}$ There have been overall attempts at reform; for example, two contributions made in this aspect during the 1996 IGC might be singled out: ${ }^{11}$

- Ireland presented a project for the reform of the Treaty. Austria, Luxembourg and Sweden backed this proposal but by the following year it had been paralysed.

- Belgium and Italy also proposed, unsuccessfully, that a chapter on energy complying with the demands of the principle of sustained growth be included in the ECT.

\section{Tracking a possible reform of the Euratom Treaty in the recent Convention}

The European Convention has addressed the issue of reforming the Euratom Treaty with extreme care from the very beginning. Nevertheless, certain proposals regarding such change have been made.

Thus, for example, a specific proposal can be found in the Appendix "Une personnalité juridique unique. L'avenir du traité EURATOM'. ${ }^{12}$ There have also been other suggestions. ${ }^{13}$ Perhaps the greatest controversy has arisen in relation to the so-called Penelope document, the proposal made by a team coordinated by F. Lamoureux and put together in response to a request by the President of the Commission, Romano Prodi, which despite its not having met with the official support of the Convention nor having been submitted on behalf of the European Commission, is undoubtedly material of interest for analysis.

Although the alternative wording of the constitutional text developed in the Penelope document lacks a general chapter on energy, it includes an additional act entitled 'the peaceful use of Atomic Energy'. This ventures an alternative wording of the Euratom Treaty - consisting basically of removing the articles no longer in use and redefining the realms of competence of the Institutions, especially the European Parliament.

\section{The destiny of Euratom, linked to the future of nuclear energy in Europe}

The EU energy strategy aims mainly to cover two principles: security of supply and environmental sustainability. The Commission's Green Paper Towards a European strategy for the security of energy supply ${ }^{14}$ establishes that the nuclear energy option cannot and must not be ruled out at Community level, and that it is the responsibility of the Member States to decide on the development of their respective nuclear power plant resources. Indeed, the energy strategy of a State is so close to the issue of national sovereignty that certain areas of competence in this domain have been assigned to the European Community only very lately. 
Energy as a Community policy was incorporated in the ECT in Maastricht, with the sole reference of Art. $3 \mathrm{I}$, surprisingly linked to other measures relating to civil protection and tourism. Among the Final Provisions of Maastricht is a Declaration relating to civil protection, energy and tourism that calls on the Commission to submit a proposal for a chapter on energy to the Council by 1996 at the latest. Certain proposals regarding this chapter were submitted at that time but did not meet with sufficient support. $^{15}$

Finally, the new constitutional text contains a section dedicated specifically to energy: section 10 of chapter III of the third part. This contains a single article, Article III-256, which is given as follows:

\section{Article III-256}

1 In the context of the establishment and functioning of the internal market and with regard for the need to preserve and improve the environment, Union policy on energy shall aim to:

a ensure the functioning of the energy market;

b ensure security of energy supply in the Union, and

c promote energy efficiency and energy saving and the development of new and renewable forms of energy.

2 Without prejudice to the application of other provisions of the Constitution, the objectives in paragraph 1 shall be achieved by measures enacted in European laws or framework laws. Such laws or framework laws shall be adopted after consultation of the Committee of the Regions and the Economic and Social Committee.

Such European laws or framework laws shall not affect a Member State's right to determine the conditions for exploiting its energy resources, its choice between different energy sources and the general structure of its energy supply, without prejudice to Article III-234(2)(c). [on the unanimous adoption of standards establishing measures significantly affecting the choice by a member State from among different energy sources and the general structure of its energy supply].

3 By way of derogation from paragraph 2, a European law or framework law of the Council shall establish the measures referred to therein when they are primarily of a fiscal nature. The Council shall act unanimously after consulting the European Parliament.

It is not the intention of this paper to analyse the scope of this new provision. However, it is necessary to touch on the implications that the final decision by the authors of the constitutional text will have for future nuclear regulation in the Community.

The respect shown by the EU for the energy options developed by the member States is a principle in keeping with the policy applied to date. However, the decision not to touch on the contents of Euratom points to certain conservatism, at least in areas such as the increase in the decision-making capacity of the Parliament. Quite another question is the possible removal from the text of articles that have never been used, as it will be necessary to consider in each case whether such articles might be of use in the future. As has already been pointed out, these are provisions that have remained dormant pending use - and their slumber has not been interrupted. 
Nevertheless, the reform of the Treaty, and with it the relationships between nuclear policy and the rest of the EU's energy policies, continues to be a red-hot issue in the debate on the future of the Union. Defining which points of nuclear energy warrant special treatment entails the greatest difficulty and will undoubtedly be the centre of all future reflections in this area.

Meanwhile, we conserve the Treaty in its present state, possibly in the understanding that a problem text is better than no text at all. The Treaty has been considered until such uncertain time in future as clear positions are adopted in relation to the development of nuclear energy in Europe, and in this aspect is similar to Shelley's serpent: Wake the serpent not - lest he/should not know the way to go (1819).

\section{Notes}

'The simplification of the Treaties was put forward as an objective for the European Union as from the Laeken Declaration (Laeken European Council, 15 December 2001). From here, numerous references will be made to the European Convention, most of the documentation of which has been published on the website http://european-convention.eu.int/bienvenue.asp?lang=ES.

${ }^{2}$ Note of the Praesidium of the Convention of 14 March 2003, doc. CONV 621/03.

${ }^{3}$ The idea was not new: during the IGC of 2000 the European Institute of Florence proposed the possibility of converting the Euratom Treaty into an Appendix of a single EUT. IGC 2000 documents, $\operatorname{COM}(2000) 434$.

${ }^{4}$ Last cycle of conferences at the EP in September 2000, an initiative of Friends of the Earth and the Heinrich Böll and Friedrich Ebert foundations. I refer to the Conference Proceedings published by Friends of the Earth Europe. For more information on the views of this organisation regarding the Treaty, refer to its website: http://www.inforse.dk/europe/eu_euratom.htm.

${ }^{5}$ It hardly needs to be pointed out that these are two sources of Primary Law and that the application of the ECT is to be understood as being without prejudice to the provisions of the Euratom Treaty, as manifested in Art. 305 ECT.

${ }^{6} \mathrm{~A}$ rundown of the state of the question can be found in GRUNWALD, Jürgen: Das Energierecht der Europäischen Gemeinschaften; Berlin in Gruyter Handbuch, 2003, p.234. No conclusive decision has been taken in this respect to date by the ECJ; it might occur in relation to the pending issue of the aid provided by the State, C 39/04 (ex N 613/2003), of the UK to the Nuclear Decommissioning Agency (Invitation to submit observations and summary of the facts in the Official Diary of the EU, 21.12.2004, C 315/4 and subsequent).

${ }^{7}$ Jürgen Grunwald reflects on this dichotomy in his *article "Euratom Vertrag: nie war er so wertvoll wie heute"; EuZW 16/2000. The idea is the same as the one reflected upon by Ayllón: Little by little, the concern [in the Euratom Treaty] for radiological protection, environmental protection and nuclear safety has become accentuated to such an extent that today these functions are, along with control of the non-proliferation of materials, those justifying its existence. The turnaround has been Copernican: from championing the strengthening of nuclear energy to guaranteeing the risk-free use of nuclear activities... (AYLLÓN DÍAZ-GONZÁLEZ, Juan Manuel: Derecho Nuclear, Granada, Comares, 1999, p.302).

${ }^{8}$ The reasons for this, as set out by Manig, centre on the different interests of France, the Commission and the other member States. Following these seven years no statement was issued on this article, and the ECJ interpreted that the chapter should be understood as remaining in force. MANIG, Wolfgang: Die Änderung der Versorgungs- und Sicherheitsvorschriften des Euratom-Vertrages durch die nachfolgende Praxis; Baden-Baden, Nomos Verlagsgesellschaft, 1. Auflage 1993; p.125. 
${ }^{9}$ The general process for the modification of Treaties is described in Art. 48 UET and can be summarised as follows:

1 The Government of a Member State or the Commission submits its reform proposal to the Council.

2 The Parliament and the Commission draw up a non-binding report regarding the proposal - for questions of Economic and Monetary Policy, the European Central Bank also issues a report.

3 The Council decides on the need to call an IGC. This decision is taken by simple majority, ex Art. 205 I ECT.

4 Within the IGC, decisions are taken on the basis of unanimity.

5 The member States ratify the new Treaty, in each case in accordance with Constitutional Law.

6 The Treaty enters into force.

These provisions are completed in a special way in the new Constitutional Treaty. Although in the IGC decisions will be taken unanimously, it will be later be sufficient for $3 / 4$ of the States of the Union make a solemn declaration accepting the new constitutional text, and that 5/6 ratify it, for it to enter into force. It is understood that those that do not ratify the text or make such a declaration shall be expelled from the Union, a possibility that had not previously been contemplated in the history of the European Community.

${ }^{10}$ Attempts have been made: Manig refers to attempts made by France or the Commission since the 1960s, but without agreement being reached within the Council. Op. cit., p.125 and subsequent.

${ }^{11}$ Sources not consulted by the author: CONF/3877/96 of 22nd July, "Discussion paper on the EURATOM Treaty in the context of EU enlargement" for the Irish proposal, and DURY/MAIJ-WEGGEN report A4-0068/96, 13 March 1996, for the Belgian and Italian proposal.

${ }^{12}$ Contribution by M. Hanne Farnleitner, M. Caspar Einem and M. Reinhard Bösch, Membres de la Convention. CONV 358/02 "nous proposons d'inclure la disposition suivante dans un futur nouveau traité:Article X:Le Conseil, statuant conformément à la procédure visée à l'article 251, arrête les mesures relatives au rapprochement des dispositions législatives, réglementaires et administratives des États membres dans le domaine de la sûreté des centrales nucléaires. Le Conseil part du principe d'un niveau de sécurité élevê".

${ }^{13}$ Other constitutional text proposals have been submitted by Brok (CONV 325/02) and Hain (CONV 345/02); both make announcements but do not develop changes in the wording of the Euratom Treaty. Finally, the contribution by Klaus Hänsch (CONV 344/02) also stresses the need to address a reform of the Euratom Treaty.

${ }^{14}$ Green Paper adopted by the Commission on 29th November $2000-\operatorname{COM}(2000) 769$ final-, available on the website http://europa.eu.int/comm/energy_transport/ doc-principal/pubfinal_es.pdf.

${ }^{15}$ Scholz/Langer, 1992, 325 Anhang III; not consulted by the author, quoted in BLECKMANN, Albert: Europarecht. Das Recht der Europäischen Union und der Europäischen Gemeinschaften. Köln, Carl Heymann Verlag, 6. Auflage, 1997. Chapter 7 of Ingo ERBERICH Energiepolitik). 